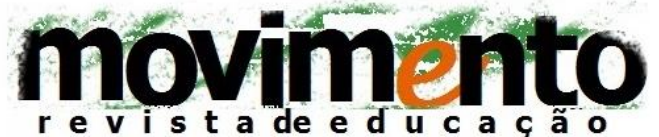 \\ faculdade de educação - programa de pós-graduação em educação \\ universidade federal fluminense \\ issn 2359-3296 \\ ano 5 número 8 - 2018
}

DOCUMENTO

\section{DEBATES E CONTROVÉRSIAS EM TORNO DA BASE NACIONAL COMUM CURRICULAR (BNCC)}

\section{Apresentação}

O documento ora apresentado reúne o Pedido de Vistas e o consequente Voto em Separado contrário das Conselheiras Aurina de Oliveira Santana, Malvina Tania Tuttman e Marcia Ângela da Silva Aguiar, na sessão de aprovação da Base Nacional Comum Curricular pelo Conselho Nacional de Educação, em 15 de dezembro de 2017. Parafraseando Luiz Carlos de Freitas, trata-se de um documento histórico, por marcar a resistência que parte da sociedade e da academia promoveram diante do açodamento para a aprovação da matéria e pela forma pouco republicana como os trabalhos foram conduzidos, impondo, de cima para baixo, um currículo engessado e claramente orientado por uma perspectiva utilitarista. Por isso, a sua publicação em um periódico acadêmico reforça sua importância como texto e como política, na contramão das reformas impostas na fragilidade democrática do Brasil. 


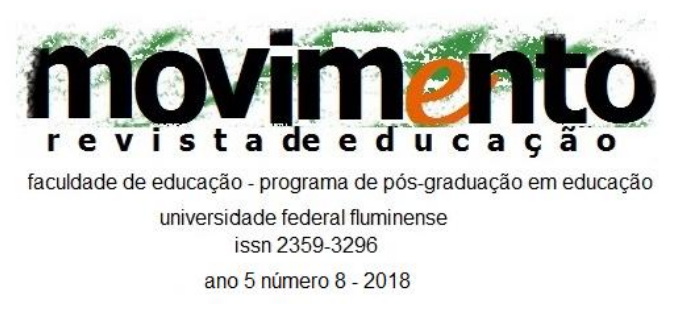

\section{PEDIDO DE VISTAS DAS CONSELHEIRAS AURINA OLIVEIRA SANTANA, MALVINA TUTTMAN E MÁRCIA ANGELA AGUIAR ${ }^{1}$}

\section{Histórico}

O Conselho Nacional de Educação (CNE) iniciou o seu processo de discussão sobre o tema da Base Nacional Comum Curricular (BNCC) constituindo uma Comissão Bicameral, criada pela Portaria CNE/CP no 11/2014, tendo por objetivo "acompanhar e contribuir com o Ministério da Educação na elaboração de documento acerca dos direitos $e$ objetivos de aprendizagem e desenvolvimento, tendo em vista, principalmente, as estratégias 2.1 e 2.2 da Meta 2 e as estratégias 3.2 e 3.3 da Meta 3 previstas no Plano Nacional de Educação aprovado pela Lei $N^{\circ} 13.005$, de 25 de junho de 2014".

Essa Comissão Bicameral da Base Nacional Comum era presidida pela Conselheira Márcia Angela da Silva Aguiar (CES/CNE), eleita pelos demais componentes do grupo, tinha como Relator o Conselheiro José Fernandes de Lima (CEB/CNE), também eleito, e ainda contava com os seguintes Conselheiros: Antonio Carlos Caruso Ronca (CEB/CNE), Antonio Cesar Russi Callegari (CEB/CNE), Erasto Fortes Mendonça (CES/CNE), Luiz Fernandes Dourado (CES/CNE), Luiz Roberto Alves (CEB/CNE), Malvina Tania Tuttman (CEB/CNE), Raimundo Moacir Mendes Feitosa (CEB/CNE), Sérgio Roberto Kieling Franco (CES/CNE) e Yugo Okida (CES/CNE). Com a saída do Conselheiro José Fernandes de Lima do CNE, a Conselheira Malvina Tuttman foi escolhida, por unanimidade, como relatora da Comissão. Com a nova composição do Conselho, decorrente de ato do Presidente Interino Michel Temer e do Ministro da Educação José Mendonça Bezerra Filho, em $1^{\circ}$ de julho de 2016, a Presidência do CNE propôs ao Conselho Pleno uma reestruturação de todas as Comissões, inclusive de suas relatorias e presidências. Dessa forma, essa Comissão Bicameral foi recomposta pela Portaria CNE/CP n ${ }^{\circ} 15 / 2016$, com o objetivo de "acompanhamento dos debates sobre a BNCC e a emissão de parecer conclusivo acerca da proposta a ser recebida pelo CNE", sendo presidida pelo Conselheiro Antonio Cesar Russi Callegari (CEB/CNE), eleito, tendo como Relatores os Conselheiros Joaquim José Soares Neto (CES/CNE) e José Francisco Soares (CEB/CNE), indicados pelo Conselho Pleno do CNE, e como membros os Conselheiros Aléssio Costa Lima (CEB/CNE), Antonio de Araújo Freitas Junior (CES/CNE), Eduardo Deschamps (CEB/CNE), Francisco Cesar de Sá Barreto (CES/CNE), Gersem José dos Santos Luciano (CEB/CNE), Ivan Cláudio Pereira Siqueira (CEB/CNE), José Loureiro Lopes (CES/CNE), Malvina Tania Tuttman (CEB/CNE), Márcia Angela da Silva Aguiar (CES/CNE), Nilma Santos Fontanive (CEB/CNE), Rafael Esmeraldo Lucchesi Ramacciotti (CEB/CNE), Raul Jean Louis Henry (CES/CNE), Rossieli Soares da Silva (CEB/CNE), Suely Melo de Castro Menezes (CEB/CNE) e Yugo Okida (CES/CNE).

Uma nova configuração foi dada à Comissão Bicameral, pela Portaria $\mathrm{CNE} / \mathrm{CP} \mathrm{n}^{\circ}$ 9/2017, com os mesmos objetivos, presidida pelo Conselheiro Antonio Cesar Russi Callegari (CEB/CNE), como Relatores os Conselheiros Joaquim José Soares Neto (CES/CNE) e José Francisco Soares (CEB/CNE), e pelos Conselheiros: Aléssio Costa

\footnotetext{
${ }^{1}$ Segundo consta no Parecer aprovado pelo CNE sobre a BNCC.
} 


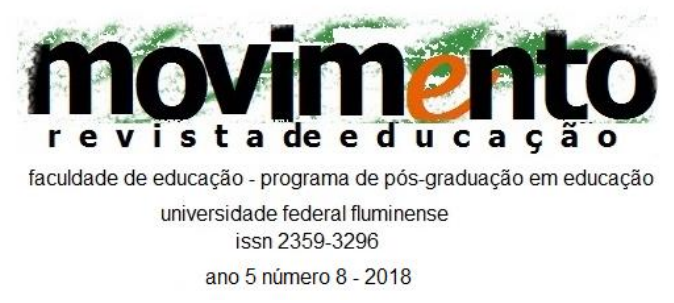

Lima (CEB/CNE), Antonio de Araújo Freitas Junior (CES/CNE), Aurina Oliveira Santana (CEB/CNE), Eduardo Deschamps (CEB/CNE), Francisco Cesar de Sá Barreto (CES/CNE), Gersem José dos Santos Luciano (CEB/CNE), Gilberto Gonçalves Garcia (CES/CNE), Ivan Cláudio Pereira Siqueira (CEB/CNE), José Loureiro Lopes (CES/CNE), Luiz Roberto Liza Curi (CES/CNE), Malvina Tania Tuttman (CEB/CNE), Márcia Angela da Silva Aguiar (CES/CNE), Nilma Santos Fontanive (CEB/CNE), Paulo Monteiro vieira Braga Barone (CES/CNE), Rafael Esmeraldo Lucchesi Ramacciotti (CEB/CNE), Rossieli Soares da Silva (CEB/CNE), Suely Melo de Castro Menezes (CEB/CNE) e Yugo Okida (CES/CNE).

Pela Portaria CNE/CP n ${ }^{\circ} 11 / 2017$, foi alterada sua composição, que é a atual, com os Conselheiros Antonio Cesar Russi Callegari (CEB/CNE), Presidente; Joaquim José Soares Neto (CES/CNE) e José Francisco Soares (CEB/CNE), Relatores; e Alessio Costa Lima (CEB/CNE), Antonio Carbonari Netto (CES/CNE), Antonio de Araujo Freitas Junior (CES/CNE), Arthur Roquete de Macedo (CES/CNE), Aurina Oliveira Santana (CEB/CNE), Eduardo Deschamps (CEB/CNE), Francisco Cesar de Sá Barreto (CES/CNE), Gersem José dos Santos Luciano (CEB/CNE), Gilberto Gonçalves Garcia (CES/CNE), Ivan Cláudio Pereira Siqueira (CEB/CNE), José Loureiro Lopes (CES/CNE), Luiz Roberto Liza Curi (CES/CNE), Malvina Tania Tuttman (CEB/CNE), Márcia Angela da Silva Aguiar (CES/CNE), Maurício Eliseu Costa Romão (CES/CNE), Nilma Santos Fontanive (CEB/CNE), Paulo Monteiro Vieira Braga Barone (CES/CNE), Rafael Esmeraldo Lucchesi Ramacciotti (CEB/CNE), Rossieli Soares da Silva (CEB/CNE), Suely Melo de Castro Menezes (CEB/CNE) e Yugo Okida (CES/CNE), membros. Dessa forma, a Comissão Bicameral é hoje formada por todos os membros do CNE.

Paralelamente à organização do CNE para análise do tema, o Ministério da Educação (MEC) já vinha desenvolvendo estudos sobre o assunto, intensificando as suas ações a partir de 2014. Nesse contexto, a Secretaria de Educação Básica (SEB) do MEC disponibilizou, para leitura restrita, o estudo "Por uma política curricular para a educação básica: contribuição ao debate da base nacional comum a partir do direito à aprendizagem e ao desenvolvimento".

Em 2015, foram iniciados novos estudos pelo MEC para a preparação de um documento sobre a BNCC. Cerca de 120 (cento e vinte) profissionais da educação, entre eles professores da Educação Básica e da Educação Superior de diferentes áreas do conhecimento, foram convidados pelo MEC para elaborar um documento que resultou na "primeira versão" da BNCC. Essa versão foi colocada em consulta pública, por meio de internet, entre outubro de 2015 e março de 2016. Segundo dados do MEC, houve mais de 12 milhões de contribuições ao texto, com a participação de cerca de

300 mil pessoas e instituições. Contou, também, com pareceres de especialistas brasileiros e estrangeiros, associações científicas e membros da comunidade acadêmica. As contribuições foram sistematizadas por profissionais da Universidade de Brasília (UnB) e da Pontifícia Universidade Católica do Rio de Janeiro (PUC-RJ), e subsidiaram o MEC na elaboração da "segunda versão".

Em maio de 2016, a "segunda versão" do documento da BNCC foi disponibilizada e submetida à discussão por cerca de 9 mil educadores em seminários realizados pela União Nacional dos Dirigentes Municipais de Educação (Undime) e pelo Conselho Nacional de Secretários de Educação (Consed), em todo o país, entre junho e agosto do mesmo ano. A metodologia de análise do documento foi efetivada por meio de discussões em salas

Movimento-Revista de Educação, Niterói, ano 5, n.8, p. 268-280, jan./jun. 2018. 


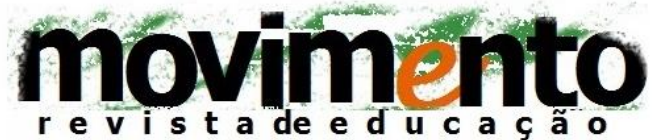 \\ faculdade de educação - programa de pós-graduação em educação \\ universidade federal fluminense \\ issn 2359-3296 \\ ano 5 número 8 - 2018}

específicas, por áreas de estudo/componentes curriculares, e coordenada por moderadores que, em sua maioria, apresentavam slides com objetivos e conteúdos e os participantes optavam por uma das seguintes alternativas: concordo, discordo totalmente ou discordo parcialmente e indicavam propostas de alteração, se fosse o caso.

O Consed e a Undime elaboraram um relatório com as contribuições advindas dos seminários e o encaminharam para o Comitê Gestor do MEC. Importante observar que o Comitê Gestor foi o responsável pelas definições e diretrizes que orientaram a revisão da "segunda versão" e que deu origem à "terceira versão", encaminhada ao CNE, em abril de 2017, focalizando a Educação Infantil e o Ensino Fundamental, sem a devida argumentação sobre o não atendimento legal ao excluir, dessa versão, o Ensino Médio. No CNE, a Comissão Bicameral que ficou encarregada pelo estudo e devido encaminhamento em relação à BNCC, em reunião realizada em 8 de maio de 2017, deliberou que promoveria 5 (cinco) audiências públicas nacionais, sendo uma em cada Região Geográfica do país, com grande participação de representantes de instituições educacionais e organizações profissionais, bem como de pessoas interessadas na discussão do tema, a saber:

Região Norte, 7 de junho de 2017, em Manaus (AM), com 228 participantes e 38 intervenções;

Região Nordeste, 28 de julho de 2017, em Recife (PE), com 428 participantes e 57 intervenções;

Região Sul, 11 de agosto de 2017, em Florianópolis (SC), com 340 participantes e 62 intervenções;

Região Sudeste, 25 de agosto de 2017, em São Paulo (SP), com 491 participantes e 54 intervenções;

Região Centro-Oeste, 11 de setembro de 2017, em Brasília (DF), com 220 participantes e 72 intervenções.

As propostas apresentadas nas cinco audiências públicas, tanto oralmente, quanto por meio de documentos, foram entregues aos organizadores e deram origem a uma planilha que agrupou os assuntos abordados.

No mês de outubro de 2017, a Comissão Bicameral do CNE encaminhou ao MEC o documento "Questões e proposições complementares ao Ministério da Educação", contendo 10 (dez) itens (questões e proposições) e o "registro de ênfases que o debate, na visão de um conselheiro, indicou como muito relevantes".

A Comissão Bicameral do CNE realizou debates que levaram à proposição de sugestões e alterações no documento, sugerindo, entre outros assuntos, a inclusão de temáticas voltadas para as populações indígenas, quilombolas e afro-brasileiras, bem como questões voltadas para a área de computação, tecnologias digitais, entre outras.

Ainda em novembro, os Relatores da Comissão Bicameral apresentaram, cada um, uma minuta de parecer para apreciação. Os Conselheiros e Conselheiras, enquanto membros da Comissão, encaminharam a proposta de ser analisado apenas um documento na reunião de dezembro, procurando um possível consenso entre as minutas relatadas. Essa situação inédita já sinalizava a complexidade da matéria e a necessidade de discussão pormenorizada pela Comissão Bicameral e, posteriormente, pelo Conselho Pleno do CNE.

Importante ressaltar que o documento base, contendo 8 (oito) anexos, utilizado pelos Conselheiros Relatores para emissão do Parecer e da Resolução, só foi enviado aos membros do Colegiado no dia 29 de novembro de 2017, via Secretaria Executiva do CNE. Este fato, 


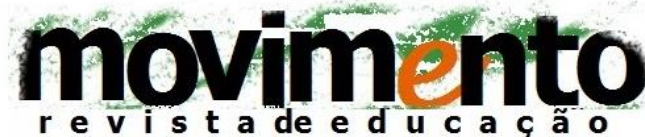 \\ faculdade de educação - programa de pós-graduação em educação \\ universidade federal fluminense \\ issn 2359-3296 \\ ano 5 número 8 - 2018}

aliado a necessidade de análise detida do referido material, foi amplamente sinalizado na reunião de dezembro, tendo sido destacado, inclusive, a falta de tempo para leitura atenta dos documentos.

Nas reuniões da Comissão Bicameral no mês de dezembro foram apresentadas pelo MEC as inclusões feitas na BNCC pelo Comitê Gestor e suas equipes, segmentadas por componente curricular, de forma individualizada e oralmente. Não foram apresentadas justificativas por escrito para a não inclusão de contribuições ocorridas nas audiências públicas e mesmo as apresentadas pelo CNE. Mais uma vez, é fundamental assinalar os limites da referida tramitação da matéria. No momento da apresentação, o MEC ainda recebeu contribuições de Conselheiros e Conselheiras e se comprometeu a incluir algumas delas no documento da BNCC. Este processo não permitiu uma análise pormenorizada das inclusões, por parte da Comissão e do CNE, como requer a matéria, sobretudo, se considerarmos a substantiva contribuição advinda das audiências públicas.

Em seguida, os Relatores leram a minuta do Parecer, que incorporou as proposições das 2 (duas) minutas apresentadas na reunião da Comissão de novembro. Os Conselheiros e Conselheiras fizeram destaques durante a leitura. Posteriormente, cada destaque foi apresentado e encaminhado por escrito aos Relatores para as suas apreciações. Dado a complexidade da temática, os vários destaques e o pouco tempo para a discussão, houve a necessidade de adiar a reunião do Conselho Pleno, onde o Parecer e a Resolução deveriam ser lidos publicamente e apreciados, pois a Comissão ainda não havia concluído suas análises e encaminhamentos.

O terceiro dia de reunião da Comissão Bicameral foi de discussão, sendo distribuída a segunda versão do Parecer e da Resolução já em seu término, e ainda recebendo contribuições aos textos. Por esse motivo, a reunião da Comissão precisou ser concluída no início da manhã do quarto dia, sendo que mais duas minutas de Parecer e Resolução foram entregues aos membros da Comissão, sem tempo para análise. Essas várias versões não foram suficientemente analisadas, o que, certamente, prejudicou a tramitação e discussão da matéria. As buscas da celeridade na tramitação, sobretudo, das minutas de Parecer e da Resolução, se sobrepuseram ao papel do CNE como órgão de Estado, comprometendo a discussão e eventuais ajustes e contribuições às minutas.

A reunião do Conselho Pleno foi iniciada tardiamente com a participação do público. No início da Sessão, as Conselheiras Márcia Angela da Silva Aguiar (CES/CNE), Malvina Tania Tuttman (CEB/CNE) e Aurina Oliveira Santana (CEB/CNE) protocolaram, junto ao Presidente do CNE, o pedido de vista das minutas de Parecer e da Resolução por considerarem que a BNCC não estava concluída, assim como, existiam questionamentos e dúvidas quanto a estes documentos que precisavam ser melhor discutidos e aprofundados pelo CNE. Uma questão que permeou todo o debate da $3^{\text {a }}$ versão da BNCC, no CNE, foi a exclusão do Ensino Médio, como assinalado anteriormente, à medida em que esta versão se delimitou à Educação Infantil e ao Ensino Fundamental, não atendendo, desse modo, as exigências legais.

Mesmo tendo protocolada a solicitação, as referidas Conselheiras foram informadas pelo Presidente do CNE que deveriam pedir vista publicamente, antes do processo de votação. Assim o fizeram, de acordo com o artigo 32 do Regimento Interno do CNE.

O Presidente do CNE, antes de atender ao disposto no art.32 do Regimento, concedeu a palavra a um Conselheiro que requereu votação de matéria em regime de urgência, baseado 


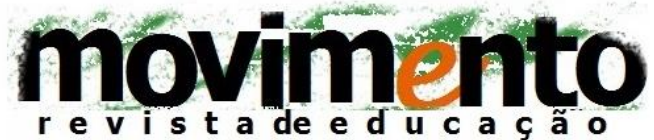 \\ faculdade de educação - programa de pós-graduação em educação \\ universidade federal fluminense \\ issn 2359-3296 \\ ano 5 número 8 - 2018}

no art. 15, inciso III, do referido Regimento. Questionado por ter colocado em votação o regime de urgência antes do pedido de vista, o Presidente do CNE argumentou que o referido pedido de urgência tinha sido solicitado na véspera, por escrito, e assinado por um conjunto de Conselheiros. Após esse ato, concedeu o pedido de vista e encerrou a Sessão.

Depois do término da Sessão do Conselho Pleno, o Presidente do CNE informou às Conselheiras que solicitaram vista do Parecer e da Resolução que, o prazo para a apresentação do substitutivo era de 1 (uma) semana, agendando a próxima reunião do Conselho, com caráter deliberativo, para o dia 15/12/2017, das $9 \mathrm{~h}$ às $18 \mathrm{~h}$. Importante salientar que o prazo definido é um excelente sinalizador da opção da Presidência do CNE pela celeridade na tramitação e eventual aprovação da BNCC, em detrimento a uma análise detida, requerida por um pedido de vista de matéria de grande importância para a agenda nacional.

\section{Análise de Mérito}

A partir do contexto histórico apresentado, serão destacados nesta análise alguns aspectos presentes tanto na metodologia de elaboração adotada pelo MEC para a construção da BNCC, que privilegia especialistas e subalterniza o diálogo com as comunidades educacionais e escolares, em um modelo centralizador de tomada de decisões, quanto nos seus consensos e dissensos que não foram suficientemente e pedagogicamente tratados como requer a matéria.

\subsection{Metodologia de Construção da BNCC}

A opção de construção da BNCC adotou uma metodologia verticalizada, a qual foi denominada de participativa. Para essa análise, considera-se o início propriamente dito de elaboração do atual documento apresentado pelo MEC, quando este constitui um grupo de profissionais para apresentar, sem um marco de referência que desse unidade ao trabalho, uma primeira versão do documento, por componente curricular.

Para a definição de ações educacionais, seja a nível governamental ou de instituições educativas e escolares, é necessário ter um marco de referência, que represente as concepções, utopias, os sonhos, os princípios educacionais desejados e definidos coletivamente. Mais do que números, é fundamental uma interpretação qualificada. É preciso conhecer o que nos revelam os dados e os microdados para a elaboração de um verdadeiro diagnóstico da educação. É preciso, ainda, refletir sobre o que está sendo realizado, o que é desejável e necessário para as crianças, os adolescentes, os jovens e os adultos do nosso país. As concepções, alicerçadas em princípios educacionais, a serem amplamente debatidas, se articulam aos sonhos, as utopias de resgate da dívida histórica do Estado brasileiro para com a educação nacional e, nesse caso, para a definição dos objetivos de aprendizagem e desenvolvimento. A construção desses referenciais deve se efetivar de forma republicana.

Não é incomum a adoção de medidas imediatistas, desvinculadas de um planejamento pautado em marcos de referência e nos diagnósticos, como é o caso da BNCC, que desde o seu início privilegia um conjunto de conteúdos e objetivos sem o fundamental suporte de uma referência que deixe claro o projeto de nação e educação desejadas.

Usuários desse modelo acreditam que cartilhas, guias como "receitas", a serem reproduzidos nas escolas, serão "remédio" infalível para os "males" da educação. Surgem, então, propostas que desconsideram o grande potencial de nossas comunidades educacionais 


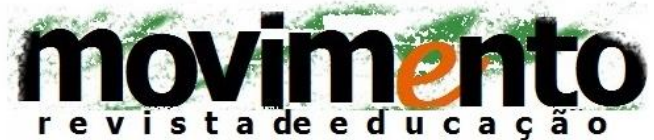 \\ faculdade de educação - programa de pós-graduação em educação \\ universidade federal fluminense \\ issn 2359-3296 \\ ano 5 número 8 - 2018}

e escolares.

Depois de elaborada a "primeira versão" da BNCC, a mesma foi submetida a uma apreciação pública, sendo a maior parte das contribuições individualizadas, sem passar por um processo coletivo de discussão. Posteriormente, o MEC analisou a sistematização das contribuições e definiu o que seria incorporado ao documento, originando a "segunda versão".

Cabe a pergunta: qual o marco de referência que serviu de parâmetro para as escolhas do MEC?

Da mesma forma, a "segunda versão" da BNCC foi publicizada, agora sob a coordenação da Undime e do Consed, que organizaram os seminários por todo o país, mas utilizando a mesma premissa de participação. O documento foi apresentado por componentes curriculares e os participantes, agora por grupos específicos, concordaram ou discordaram do que lhes foi apresentado. Continuou sendo uma forma tênue de participação. A metodologia se repetiu. O MEC, com a formalização de um Grupo Gestor, definiu quais contribuições seriam acolhidas. Surgiu, então, a "terceira versão", que foi apresentada ao CNE para análise. Fica clara a metodologia de construção linear, vertical e centralizadora. Importante situar, ainda, que a nova proposta não cumpriu com as exigências legais ao excluir uma das etapas da Educação Básica: o Ensino Médio.

\subsection{Base: Consensos e Dissensos}

A temática Base Nacional Comum não é um assunto novo. Está prevista na Constituição de 1988 para o Ensino Fundamental, e foi ampliada para o Ensino Médio com a aprovação do Plano Nacional de Educação (PNE), a partir da Lei 13.005/2014, em consonância com a Lei n ${ }^{\circ}$ 9.394, de 20 de dezembro de 1996 - LDB, que define as Diretrizes e Bases da Educação Nacional.

Em nossa história recente de organização da educação, identificamos propostas que se assemelham ao que hoje se denomina de Base Nacional Comum. Por exemplo, na década de 1980, surgiram os "Guias Curriculares", nos anos 90, os "Parâmetros Curriculares". Neste percurso histórico, as "Diretrizes Curriculares Nacionais" constituíram-se em efetivo avanço na agenda educacional ao delinear as concepções político-pedagógicas para todas as etapas e modalidades da Educação Básica, em atendimento ao previsto na atual LDB, contribuindo, efetivamente, para a implantação da nova estrutura de educação então instituída.

O CNE, desde a promulgação da LDB/1996, tem se dedicado ao cumprimento das competências que lhe são atribuídas pelo art. $9^{\circ}, \S 1^{\circ}$, alínea "c" da Lei Federal n ${ }^{\circ}$ 9.131/95

e pelo art. 90 da LDB, para a definição de Diretrizes Curriculares Nacionais.

Em 2001, o CNE elaborou e divulgou uma coletânea com as Diretrizes Curriculares Nacionais aprovadas até aquele momento pela sua Câmara de Educação Básica, e homologadas pelo então senhor Ministro de Estado da Educação. Nesta coletânea, ficam claras a importância e as finalidades destas Diretrizes.

Importante destacar algumas afirmativas desse Documento, registradas em sua introdução:

(i) as Diretrizes caracterizam-se como conjuntos articulados de princípios, critérios e procedimentos que devem ser observados pelos sistemas de ensino e pelas escolas na organização e no planejamento, na execução e na avaliação de seus cursos e respectivos projetos pedagógicos. Esta é uma orientação da nova legislação educacional brasileira;

Movimento-Revista de Educação, Niterói, ano 5, n.8, p. 268-280, jan.jun. 2018. 


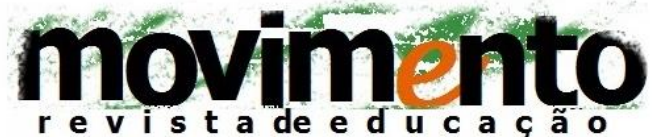 \\ faculdade de educação - programa de pós-graduação em educação \\ universidade federal fluminense \\ issn 2359-3296 \\ ano 5 número 8 - 2018}

(ii) não cabe mais a este Colegiado fixar mínimos curriculares nacionais por curso ou modalidade de ensino. Cabe, sim, fixar Diretrizes Curriculares Nacionais que orientem os sistemas de ensino na tarefa de apoiar o desenvolvimento dos projetos pedagógicos concebidos, executados e avaliados pelas escolas, com a efetiva participação de toda a comunidade escolar, em especial dos docentes;

(iii) deve haver "flexibilidade para atuação dos sistemas de ensino e das escolas, de todos os níveis e modalidades, bem como apoio, orientação e avaliação da qualidade do ensino por parte do Poder Público [...] ao lado do zelo pela aprendizagem dos alunos e do compromisso com resultados, em termos de desenvolvimento da capacidade de aprendizagem e de constituição de competências que conduzam o aluno à progressiva autonomia intelectual e o coloque em condições de continuar aprendendo.

Entre os anos de 2009 e 2011 foram elaboradas e aprovadas pelo CNE Diretrizes Nacionais Curriculares para a Educação Infantil, para o Ensino Fundamental e para o Ensino Médio, e homologadas pelo MEC.

Em 2017, o MEC encaminha ao CNE a $3^{\text {a }}$ versão da Base Nacional Comum Curricular, elaborada de forma autônoma pelo Comitê Gestor. Nesta nova versão, muitos limites são detectados e destacados nas audiências públicas regionais, efetivadas pelo CNE. A análise detida dessas contribuições não se efetivou e a tramitação célere da matéria na Comissão Bicameral, como destacamos, comprometeu o processo de discussão e deliberação resultando, entre outros, no pedido de vista.

Essas considerações têm a intenção de resgatar a memória do presente debate, que é histórico, e de onde emergem consensos e dissensos. Para tanto, cabem algumas questões: para que serve esse Documento? Para quem? A partir de qual concepção? Há conversa com Documentos anteriores? Quais os possíveis avanços?

Outro conjunto de questões parece ser necessário: o que se entende por formação humana, para além da dimensão cognitiva? Qual o projeto de sociedade que embasa o Documento? A proposta articula, como definido no PNE, os objetivos de aprendizagem e desenvolvimento ou se restringe a aprendizagem? A BNCC sendo direcionada a Educação Básica não deveria contemplar o Ensino Médio, como definido nos dispositivos legais?

A esse respeito é singular a análise de Cury (2008) sobre a educação básica ao afirmar que:

A expressão "educação básica" no texto de uma Lei de Diretrizes e Bases da Educação Nacional - LDBEN - é um conceito, é um conceito novo, é um direito e também uma forma de organização da educação nacional. Como conceito, a educação básica veio esclarecer e administrar um conjunto de realidades novas trazidas pela busca de um espaço público novo. Como um princípio conceitual, genérico e abstrato, a educação básica ajuda a organizar o real existente em novas bases e administrá-lo por meio de uma ação política consequente. A capacidade de mobilização de uma idéia política reside justamente nos seus conteúdos abstratos. Aliás, a abstração é fonte fundamental de sua força, porque permite que os conteúdos de determinados princípios gerais possam ganhar redefinições inesperadas, e, portanto, a questão dos direitos será sempre uma construção imperfeita e inacabada. (Rego, 2006, p.184) E como a todo conceito corresponde um termo, vê-se que, etimologicamente, "base", donde procede a expressão "básica", confirma esta acepção de conceito e etapas conjugadas sob um só todo. "Base" provém do grego básis, eós e

Movimento-Revista de Educação, Niterói, ano 5, n.8, p. 268-280, jan.jun. 2018. 


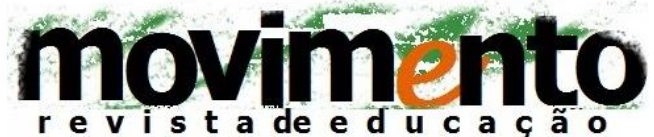 \\ faculdade de educação - programa de pós-graduação em educação \\ universidade federal fluminense \\ issn 2359-3296 \\ ano 5 número 8 - 2018}

corresponde, ao mesmo tempo, a um substantivo: pedestal, fundação, e a um verbo: andar, pôr em marcha, avançar. Como conceito novo, ela traduz uma nova realidade nascida de um possível histórico que se realizou e de uma postura transgressora de situações preexistentes, carregadas de caráter não democrático. Como direito, ela significa um recorte universalista próprio de uma cidadania ampliada e ansiosa por encontros e reencontros com uma democracia civil, social, política e cultural. E é aí que se situa o papel crucial do novo conceito inclusive como nova forma de organização da educação escolar nacional. E é aí que se situa o papel crucial do novo conceito inclusive como nova forma de organização da educação escolar nacional.

Essa nova forma atingiu tanto o pacto federativo quanto a organização pedagógica das instituições escolares. Esse papel o é como tal porque à educação lhe é imanente o de ser em si um pilar da cidadania e o é inda mais por ter sido destinado à educação básica o condão de reunir as três etapas que a constituem: a educação infantil, o ensino fundamental e o ensino médio. A educação básica é um conceito mais do que inovador para um país que, por séculos, negou, de modo elitista e seletivo, a seus cidadãos, o direito ao conhecimento pela ação sistemática da organização escolar.

É preciso pensar a educação em sua totalidade. Temos a convicção de que currículo, a partir de diretrizes nacionais, é definido nas instituições educativas e escolas, construído a muitas mãos, a partir das várias histórias de vida que fazem parte desse cotidiano. As concepções, saberes, conteúdos e as metodologias não fazem sentido se desconectadas daquele contexto. Os estudantes e os profissionais da educação devem ter assegurado seu protagonismo. É preciso refundar saberes, ampliando, verdadeiramente, o conhecimento da realidade, como delineado nos dispositivos legais e nas Diretrizes Curriculares Nacionais (DCN) para a Educação Básica.

O PNE, especialmente nas Metas 2, 3 e 7 - estratégias 2.1; 3.2 e 7.1, respectivamente, indicam a atribuição do MEC, em articulação com os estados, Distrito Federal e municípios, de encaminharem ao CNE diretrizes pedagógicas para a Educação Básica e a base nacional comum dos currículos, respeitadas a diversidade regional, estadual e local.

Alguns caminhos poderiam ser tomados para atender ao PNE. Um deles, utilizando a metodologia que está sendo adotada, privilegia uma centralidade de um Documento cuja lógica e dinâmica pedagógica atenta para os objetivos de aprendizagem descolados do desenvolvimento, como definido no PNE. Outro caminho, implicaria no aprofundamento das discussões e melhoria do Documento por meio da busca de efetiva conexão deste com a definição legal de direitos e objetivos de aprendizagem e desenvolvimento. Este segundo caminho, já destacado pelas Conselheiras em várias ocasiões, teriam por centralidade a discussão e retomada dos referenciais das atuais Diretrizes Curriculares, emanadas do CNE, em um desenho pedagógico que permita uma unidade nacional sem prescindir da diversidade, possibilitando que articule direitos e objetivos de aprendizagem e desenvolvimento e, ao mesmo tempo, reforce o protagonismo dos profissionais da educação na elaboração de propostas curriculares das instituições e escolas. Isso já está posto na Coletânea do CNE de 2001, citada no presente texto. Caberia, portanto, a elaboração de diretrizes para que as Secretarias de Educação, em conjunto com as instituições educativas e escolas e as representações sociais, implementassem as atuais Diretrizes sem o risco de um estreitamento curricular, atendendo o que também está previsto no PNE, no que se refere às

Movimento-Revista de Educação, Niterói, ano 5, n.8, p. 268-280, jan.jun. 2018. 


\section{movimento \\ faculdade de educação - programa de pós-graduação em educação \\ universidade federal fluminense \\ issn 2359-3296 \\ ano 5 número 8 - 2018}

diversidades regionais, estaduais e locais, além da necessária articulação entre direitos e objetivos de aprendizagem e desenvolvimento.

Nessa direção, nunca é demais situar que a BNCC deve considerar as diretrizes do PNE, expressas no Art. 2 dessa Lei.

Art. $2^{\circ}$ São diretrizes do PNE:

I - erradicação do analfabetismo;

II - universalização do atendimento escolar;

III - superação das desigualdades educacionais, com ênfase na promoção da cidadania e na erradicação de todas as formas de discriminação;

IV - melhoria da qualidade da educação;

$V$ - formação para o trabalho e para a cidadania, com ênfase nos valores morais e

éticos em que se fundamenta a sociedade;

VI - promoção do princípio da gestão democrática da educação pública;

VII - promoção humanística, científica, cultural e tecnológica do País; VIII estabelecimento de meta de aplicação de recursos públicos em educação como proporção do Produto Interno Bruto - PIB, que assegure atendimento às

necessidades de expansão, com padrão de qualidade e equidade; IX - valorização dos (as) profissionais da educação;

$X \quad$ - promoção dos princípios do respeito aos direitos humanos, à diversidade e à sustentabilidade socioambiental.

De igual modo, é fundamental não perder de vista que a BNCC deve expressar proposição consoante aos artigos 205 e 206 da Constituição Federal que envolve a compreensão da educação como direitos de todos, visando o pleno desenvolvimento da pessoa, seu preparo para a cidadania e qualificação para o trabalho, bem como os princípios base para o ensino.

Art. 205. A educação, direito de todos e dever do Estado e da família, será promovida e incentivada com a colaboração da sociedade, visando ao pleno desenvolvimento da pessoa, seu preparo para o exercício da cidadania e sua qualificação para o trabalho.

Art. 206. O ensino será ministrado com base nos seguintes princípios: I - igualdade de condições para o acesso e permanência na escola;

II - liberdade de aprender, ensinar, pesquisar e divulgar o pensamento, a arte e o saber;

III - pluralismo de idéias e de concepções pedagógicas, e coexistência de instituições públicas e privadas de ensino;

IV - gratuidade do ensino público em estabelecimentos oficiais;

$V$ - valorização dos profissionais da educação escolar, garantidos, na forma da lei, planos de carreira, com ingresso exclusivamente por concurso público de provas e títulos, aos das redes públicas; (Redação dada pela Emenda Constitucional $n^{\circ} 53$, de 2006)

VI - gestão democrática do ensino público, na forma da lei; VII - garantia de padrão de qualidade.

VIII - piso salarial profissional nacional para os profissionais da educação escolar pública, nos termos de lei federal. (Incluído pela Emenda Constitucional $n^{\circ} 53$, de 2006)

Parágrafo único. A lei disporá sobre as categorias de trabalhadores considerados profissionais da educação básica e sobre a fixação de prazo para a elaboração ou adequação

Movimento-Revista de Educação, Niterói, ano 5, n.8, p. 268-280, jan./jun. 2018. 


\section{movimențo \\ faculdade de educação - programa de pós-graduação em educação \\ universidade federal fluminense \\ issn 2359-3296 \\ ano 5 número 8 - 2018}

de seus planos de carreira, no âmbito da União, dos Estados, do Distrito Federal e dos Municípios. (Incluído pela Emenda Constitucional $n^{o}$ 53, de 2006).

Além dessa breve análise, outras variáveis precisam ser consideradas quando se deseja a garantia de qualidade social da educação. Para tanto, o processo de construção da BNCC deve se efetivar por meio de proposição pedagógica que tenham por eixo as DCNs para a Educação Básica expressos em conjunto articulado de princípios, critérios e procedimentos a serem observados pelos sistemas de ensino, pelas instituições e escolas na organização e no planejamento, na execução e na avaliação de seus projetos pedagógicos e curriculares. Assim, à BNCC não cabe fixar mínimos curriculares nacionais ou engessar a ação pedagógica com objetivos de aprendizagem dissociados do desenvolvimento integral do estudante que limitam o direito a educação e, ao mesmo tempo, a aprendizagem. É importante considerar, como eixo fundamental de uma proposta de direitos e objetivos de aprendizagem e desenvolvimento, a garantia dos princípios constitucionais de liberdade de aprender, ensinar, pesquisar e divulgar o pensamento, a arte e o saber, bem como o pluralismo de ideias e de concepções pedagógicas.

Todas essas proposições se articulam a garantir a democratização do acesso e permanência do estudante nas instituições educativas com condições de participação e aprendizagem e desenvolvimento, visando superar as sérias assimetrias regionais e sociais.

Nessa direção, é fundamental assegurar o financiamento adequado da Educação Básica face a uma distribuição mais justa de recursos para a garantia da materialização do direito a educação e as metas e estratégias do PNE, o que inclui, entre outros, a universalização da Educação Básica obrigatória, educação em tempo integral, a instituição do Sistema Nacional de Educação (SNE), a valorização dos profissionais da educação, a instituição de Sistema Nacional de Avaliação da Educação Básica que contemple concepção de avaliação diagnóstica e formativa. É preciso valorizar concretamente o professor, com planos de cargos e salários dignos, ao mesmo tempo em que se busca uma formação inicial e continuada compatível com o projeto claro de sociedade desejado, como já previsto na Resolução CNE/CP n ${ }^{\circ} 2$, de $1^{\circ}$ de julho de 2015.

Afinal, quem conduz os processos curriculares são os profissionais da educação. Não há força suficiente para as mudanças necessárias sem estes coletivos. É preciso acreditar e investir seriamente na valorização destes profissionais.

Concluímos com uma afirmativa: a definição clara do Sistema Nacional de Educação (SNE), situando o papel da União na coordenação das políticas educacionais, em colaboração com os demais entes federados, permitirá assegurar que as ações não sejam mais discutidas e implementadas isoladamente, mas fazendo parte de um conjunto de políticas articuladas e, por isso, coerentes com o ideal de uma educação emancipadora.

As Conselheiras que subscrevem o presente Parecer poderiam apresentar um texto mais analítico, fundamentado e propositivo, a partir do conjunto importante de informações, dados e contribuições provenientes das audiências públicas, das reuniões com o MEC, dos encontros com representações sociais e educacionais, dos destaques e emendas realizadas pelos Conselheiros ao longo das últimas reuniões da Comissão Bicameral. Porém, alguns documentos só foram disponibilizados a partir de solicitação das referidas Conselheiras. Outros, encaminhados a pedido do Presidente do CNE, como, por exemplo, os Documentos digitalizados relativos às emendas apresentadas na Sessão do dia 7/12/2017, bem como o 


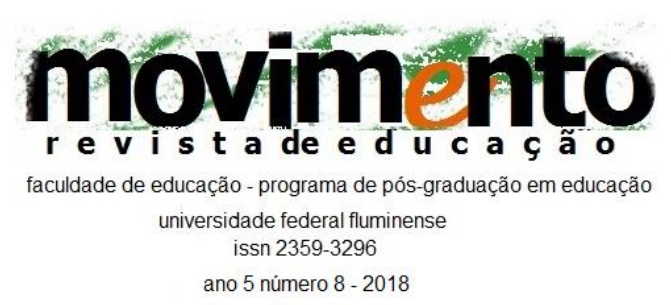

Relatório de emendas à BNCC e ao Parecer e à Resolução, enviados por meio eletrônico somente no dia 13/12/2017, faltando apenas dois dias para a Sessão do Pleno, marcada arbitrariamente com o intervalo de uma semana. Registramos, também, a ausência, neste Relatório, de emendas da Conselheira Malvina Tuttman que foram entregues aos Relatores e também à Secretária da Comissão Bicameral, em mãos.

Assim, ao pedir vista, fomos surpreendidas pela urgência e pela definição intempestiva da Presidência do CNE concedendo apenas uma semana para a elaboração de um substitutivo do Processo e da Resolução da semana destinada a apresentação de um novo Parecer, como foi referido anteriormente, prejudicando a análise de toda a documentação. Esse fato não se justifica e traz constrangimentos, uma vez que compete a esse Órgão de Estado tratar adequadamente as políticas públicas de nosso país, sem açodamento. Infelizmente, a opção do CNE foi pela celeridade em detrimento de discussão aprofundada, como requer a matéria, e isso ficará registrado como uma afronta a esse Órgão Colegiado, sobretudo, se o entendermos como um Órgão de Estado e não de Governo.

\section{IV - VOTO DO PEDIDO DE VISTAS}

Diante das razões expostas no histórico e na análise de mérito, destacando especialmente a forma aligeirada como foi conduzida a Sessão Deliberativa do Conselho Pleno, ocorrida no dia 7 de dezembro de 2017, somos contrárias à aprovação intempestiva do Parecer, seu Projeto de Resolução e anexos, considerando a sua incompletude e limitações e, portanto, a necessidade de ampliar o diálogo democrático para assegurar a qualidade social da educação básica em nosso país. Submetemos o voto ao Conselho Pleno para decisão.

Brasília (DF), 15 de dezembro de 2017

Conselheira Aurina Oliveira Santana

Conselheira Malvina Tania Tuttman

Conselheira Márcia Angela da Silva Aguiar 


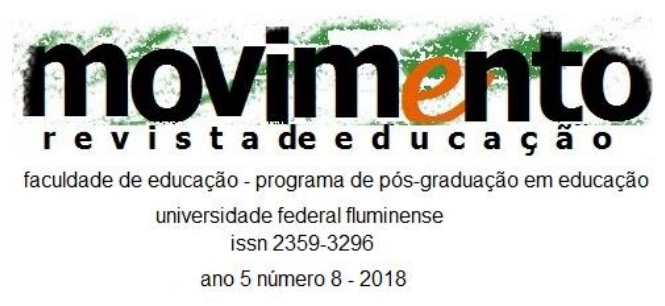

\section{DECLARAÇÕES DE VOTO DAS CONSELHEIRAS DURANTE APROVAÇÃO DA BNCC ${ }^{1}$}

\section{Conselheira Márcia Angela da Silva Aguiar}

Declaro meu voto contrário ao Parecer referente à Base Nacional Comum Curricular (BNCC) apresentado pelos Conselheiros Relatores da Comissão Bicameral da BNCC, José Francisco Soares e Joaquim José Soares Neto, alegando que o mesmo rompe com o princípio conceitual de Educação Básica ao excluir a etapa do Ensino Médio e minimizar a modalidade EJA, e a especificidade da educação no campo; desrespeita o princípio do pluralismo proposto pela Lei de Diretrizes e Bases da Educação Nacional (LDB); fere o princípio de valorização das experiências extraescolares; afronta o princípio da gestão democrática das escolas públicas; atenta contra a organicidade da Educação Básica necessária à existência de um Sistema Nacional de Educação (SNE). Declaro, ainda, que o Conselho Nacional de Educação, ao aprovar o Anexo (documento - $3^{\mathrm{a}}$ versão da BNCC) apresentado pelo Ministério da Educação, com lacunas e incompletudes, abdica do seu papel como órgão de Estado; fragiliza a formação integral dos estudantes, além de ferir a autonomia dos profissionais da Educação. Isto posto, reitero meu voto contrário à aprovação da Base Nacional Comum Curricular nos termos dos Parecer, Resolução e Anexos apresentados pelos Conselheiros Relatores.

\section{Conselheira Aurina Oliveira Santana}

Declaro que sou contrária à aprovação do Parecer da BNCC por entender que o Ensino Médio deveria integrar a Base Nacional Comum Curricular, e endosso integramente o pronunciamento da Conselheira Márcia Angela da Silva Aguiar. Dito isso, reitero o meu voto contrário ao Parecer e Resolução nos termos em que foram apresentados.

\section{Conselheira Malvina Tania Tuttman}

Declaro publicamente o meu voto divergente ao Perecer apresentado, observando que o CNE deve exercer o papel de órgão de Estado e não de governo, como demonstrou e se manifestou neste momento ao aprovar documentos incompletos. Considero, ainda, que o documento relatado apresenta importantes limitações, entre elas a ruptura da Educação Básica. Com esses argumentos, reitero o meu posicionamento contrário ao Parecer, por ser favorável ao diálogo democrático e republicano, como princípio que fundamenta a minha trajetória de quase cinquenta anos com professora deste país. Concluo, afirmando que lutarei para que o diálogo democrático e republicano aconteça em todos os espaços e recantos do Brasil, inclusive neste colegiado.

\footnotetext{
${ }^{1}$ Segundo consta no Parecer aprovado pelo CNE sobre a BNCC.
} 